\title{
Presente e Futuro da Psicologia
}

\section{Present and Future of Psychology}

\section{Presente y Futuro de la Psicología}

\author{
Roberto Moraes Cruz \\ Universidade Federal de Santa Catarina, SC, Brasil.
}

Dados do infográfico do Conselho Federal de Psicologia (CFP), atualizados em 17 de outubro de 2016, mostram que, no Brasil, 282.498 psicólogos estão inscritos nos CFPs (CFP, 2016). Ou seja, rapidamente atingiremos a marca de 300.000 psicólogos brasileiros até o final de dessa década, uma das maiores do mundo. Ponto de partida para uma reflexão inicial acerca da qualidade da formação profissional e da formação continuada em Psicologia no Brasil, assim como seus desdobramentos em termos de produção e aplicação de conhecimentos psicológicos relevantes e necessários à sociedade. Ou seja, sobre o presente e o futuro da profissão da Psicologia no país. Crescemos muito. Amadurecemos com a mesma rapidez? Qual a qualidade do processo de profissionalização de psicólogos no país? Na base dessas questões, é possível identificar os seguintes cenários e perspectivas.

Cursos de graduação em Psicologia são responsáveis por fornecer uma formação básica e ampla em diferentes áreas do conhecimento psicológico, desejáveis e úteis à construção de uma carreira profissional. De fato, esse é o horizonte, embora a percepção de que há lacunas no processo de formação, especialmente no âmbito da relação teoria-prática, que dificultam a inserção no mundo do trabalho seja uma queixa comum entre egressos dos cursos de Psicologia. É possível identificar que, em números gerais, aproximadamente metade dos psicólogos brasileiros não atuam exclusivamente como psicólogos, isto é, complementam sua fonte de renda com outras atividades técnicas, acadêmicas ou administrativas, fato igualmente identificado na primeira pesquisa de caráter nacional, promovido pelo CFP e publicado no livro "Quem é o psicólogo brasileiro?” (Bastos \& Gomide, 1989). Quais implicações tem esse fato no processo de profissionalização dos psicólogos?

A qualidade dos processos de ensino-aprendizagem na graduação, o baixo consenso sobre quais devem ser as diretrizes curriculares orientadoras da formação de psicólogos no país, a cultura pouco sólida de formação continuada e a escassez de programas de formação de professores de Psicologia são, certamente, fatores importantes a serem considerados na discussão sobre as restrições e dificuldades enfrentadas pelos psicólogos na construção e manutenção de uma carreira profissional profícua.

No âmbito da formação profissional básica, verificam-se mudanças curriculares sem o devido planejamento do ensino orientado para as perspectivas de inserção do psicólogo no mundo do trabalho (prestação de serviços para as instituições e comunidade) e, muitas vezes, descoladas das Diretrizes Curriculares Nacionais (DCN) para a área da Psicologia. Há uma redução, cada vez mais acentuada nos fluxos curriculares, de disciplinas metodológicas e técnicas e voltadas à intervenção psicológica, assim como uma valorização de conteúdos programáticos e de experiências mais genéricas que, embora possam ser enriquecedores para a formação geral do cidadão (as chamadas disciplinas transversais ou temas diversos), restringem cada vez mais o ensino e o desenvolvimento de competências específicas à atuação dos psicólogos. A carência de programas de formação de professores em Psicologia, de metodologias de programação de ensino, de avaliação de processos de ensino-aprendizagem e da inserção dos egressos dos cursos de Psicologia acentuam a generalização de opiniões sobre o que deve ser 
ensinado e como devem ser ensinados os conteúdos programáticos de matérias psicológicas e afins.

Disciplinas do denominado núcleo comum, presumivelmente aquele que mantém, em seu domínio, as chamadas disciplinas básicas para a formação do psicólogo, são menos prestigiadas na contratação de novos docentes, em detrimentos das chamadas ênfases curriculares. Assim, geralmente há uma menor estabilidade de professores no núcleo comum, cujas disciplinas são ocupadas por professores menos experientes, estagiários docentes, professores temporários e assemelhados. Com isso, aparentemente sai fortalecido o espectro profissionalizante do currículo, mas que sofre influência exatamente das lacunas na formação do núcleo comum. Ainda assim, não é incomum, nos estágios curriculares, perceber a angústia dos alunos por não saber como agir em situações típicas da intervenção profissional do psicólogo (promover a atenção e cuidados, entrevistar, administrar uma anamnese, avaliar e elaborar diagnósticos, redigir documento psicológico segundo seu objeto, finalidade e contexto, elaborar e comunicar raciocínio clínico, redigir relatórios técnicos, saber atuar em equipes multiprofissionais.

No auge das críticas ao currículo mínimo da Psicologia (ao longo da década de 1990), iniciou-se um processo de desconstrução dos currículos existentes, considerados, até então, excessivamente tecnicistas, por um lado, e pouco atualizado em torno dos campos emergentes da Psicologia, por outro. De fato, o aprofundamento dessa discussão, no contexto da proliferação de cursos de Psicologia no Brasil e do advento das DCN, acelerou movimentos de mudança na organização e composição dos fluxos curriculares. Há que se avaliar, desde então, se as mudanças implementadas surtiram os efeitos desejados, ou seja, uma melhor formação em Psicologia e uma ampliação da inserção do psicológico no mundo do trabalho. As pistas indicam que inseguranças e fragilidades identificadas no exercício profissional (dificuldades de inserção no mundo do trabalho, infrações ético-profissionais centrada basicamente na comunicação de informação psicológica, sem o devido fundamento científico e técnico, uso das especializações lato sensu como forma de complementação de lacunas na formação básica, baixo empreendedorismo nas chamadas áreas emergentes, dentre outras) permanecem salientes no processo de formação profissional dos psicólogos.
Além disso, currículos, por definição, são estruturas programáticas que precisam estar atentas às mudanças na sociedade e no desenvolvimento da Psicologia como ciência e da profissão, sob pena de não refletirem a realidade e dificultarem o processo de inserção dos egressos dos cursos de Psicologia no mundo do trabalho e nas diferentes especialidades em Psicologia. É assim, por exemplo, que ainda permanecem restritas, quando não ausentes nos currículos de Psicologia no Brasil, perspectivas e matérias científicas tais como Psicologia baseada em evidências, Psicofisiologia, Neurociências, Psicoimunologia, Psicofarmacologia, Ergonomia, Psicologia Ambiental, Psicologia do Esporte e do Exercício, Psicomotricidade, Psicologia Jurídica, Psicogerontologia, dentre outras.

Cursos de Psicologia, por meio de suas ações e processos de ensino-aprendizagem, devem incentivar os alunos a participarem de programas de formação continuada, especialmente os de pós-graduação (lato e stricto sensu), a fim de assegurar o desenvolvimento de habilidades específicas, assim como o fortalecimento das especialidades e o desenvolvimento técnico-científico e social da Psicologia. O domínio de assuntos e processos de intervenção específicos, para os quais os psicólogos devem estar preparados técnica e cientificamente ao longo do seu processo de profissionalização (formação básica, capacitação, treinamento), aumenta a possibilidade de prestação de serviços adequados às demandas da população e das instituições (cuidados primários, diagnóstico e tratamento de problemas saúde mental, serviços de consultoria e assessoramento em organizações públicas e privadas, avaliação de processos de aprendizagem e programas de desenvolvimento, aplicação de conhecimentos específicos na investigação e perícia de problemas psicológicos, dentre outros).

Formação e certificação profissional são processos que dependem cada vez mais de mudanças no cenário científico e mercadológico. Manter, aperfeiçoar ou criar alternativas curriculares básicas, mas, ao mesmo tempo, modernas e viáveis à inserção de psicólogos no mundo do trabalho, é um desafio permanente dos cursos de Psicologia, considerando que já há algum tempo não se tem uma discussão nacional sobre a formação de psicólogos, tal como realizada em uma das mais significativas discussões sobre Formação em Psicologia, realizada no Encontro Nacional de Cursos de Psicologia, que resultou no documento denominado Carta de Serra Negra (CFP, 1992). 
O processo de acreditação de psicólogos deverá se generalizar nas especialidades profissionais, tendo em vista a necessidade de avaliar e certificar a qualidade de serviços oferecidos por psicológicos em seus respectivos segmentos de atuação. Com a ampliação de associações e sociedades científicas e profissionais em Psicologia, verificado nos últimos anos, acentua-se a necessidade de integração e tutela de princípios, conceitos e procedimentos que constituam referências às intervenções profissionais, assim como à produção e disseminação de conhecimentos à comunidade. O processo de acreditação, dessa forma, além de ser uma forma de alinhamento e fortalecimento de áreas científicas e dos campos de atuação profissional em Psicologia, promove o interesse pela capacitação e formação continuada dos psicólogos, o que não deve ser confundido com a fiscalização e controle normativo do exercício profissional do psicólogo, cuja jurisdição pertence aos Conselhos Regionais e Federal de Psicologia.

Assim como o processo de acreditação, um aspecto que tem se apresentado de forma cada vez mais crescente é a revalidação de diplomas e a mobilidade de profissionais estrangeiros em nosso país. Esse fato desencadeado pelo movimento de integração de psicólogos de países latino-americanos, iniciado pelo CFP, em parceria com entidades representativas de psicólogos de países do Mercosul, no início da década de 1990, e consolidado no Protocolo de Princípios para a Formação de Psicólogos nos Países do Mercosul e Países Associados, propunha, entre outras coisas, "garantir uma formação básica comum para o reconhecimento de um psicólogo, em todos os países da região" (Schneider, 1998).

Revalidar um diploma estrangeiro, contudo, ainda é um processo demorado e sujeito às inúmeras variações curriculares dos cursos de Psicologia, com grandes diferenças regionais e pouco alinhamento a currículos internacionais. A necessidade de organização de um currículo mínimo ou de base nacional certamente retornará à ordem do dia, considerando as críticas acerca da implantação das DCN nos cursos de graduação. É perceptível que a criação da noção de núcleo comum e de ênfases curriculares voltadas à construção de competências profissionais e de habilidades técnicas e científicas, definidas nas DCN, não foi suficiente para dotar os currículos de uma identidade nacional. As DCN se propuseram a ser um conjunto de proposições básicas de organização de eixos comuns aos cursos de Psicologia no Brasil, na esteira da crítica ao currículo mínimo nacional, que definiu matérias específicas básicas e complementares (Brasil, 1962).

Formação generalista e diversidade de propostas teórico-metodológicas em Psicologia não refletem, na prática, conhecimento aplicado sobre como investigar, avaliar e intervir em fenômenos psicológicos por parte dos psicólogos. Processos de ensino básicos e complementares devem ser afirmativos de condutas profissionais relevantes e necessárias à atuação do psicólogo. Prospectivamente, algumas diretrizes ético-metodológicas de conduta profissional dos psicólogos parecem ser consensuais à afirmação do psicólogo no mundo do trabalho:

- Produzir conhecimento sobre fenômenos e processos psicológicos que auxiliem na compreensão da realidade humana;

- Manter-se atualizado técnica e cientificamente ao longo da vida profissional;

- Intervir em situações e problemas que exijam conhecimento psicológico, visando superar dificuldades e promover algum benefício às pessoas;

- Promover mudanças pessoais e coletivas para um estado melhor;

- Procurar não causar prejuízo ou dano às pessoas ou instituições;

- Guardar sigilo e confidencialidade como forma de preservar a vida, manter a relação de confiança e os melhores resultados para os usuários de seus serviços;

- Encaminhar a outros especialistas quando o limite de sua atuação tornar-se evidente;

- Buscar as melhores formas de comunicação oral ou por escrito para posicionar-se como psicólogo na sociedade.

Assim, pensar o presente e o futuro da Psicologia é, ao mesmo tempo, aprofundar a leitura dos desafios enfrentados pelos psicólogos no mundo do trabalho e afirmar diretrizes orientadoras da profissão para as próximas décadas.Épreciso, antes de tudo, compreender o papel da Psicologia no mundo das ciências e no futuro 
da humanidade para entender o seu próprio desenvolvimento (Cassepp-Borges, 2013). Significa, de fato, compreender o papel dos conhecimentos científicos acumulados na área, tornando-os acessíveis aos alunos, aperfeiçoar habilidades conceituais (para conhecer e

\section{Referências}

Bastos, A. V. B. \& Gomide, P. I. C. (1989). O psicólogo brasileiro: sua atuação e formação profissional. Psicol. Cienc. Prof., v.9, n.1, pp.6-15.

Brasil (1962). Ministério da Educação. Resolução de 19 de dezembro de 1962. Currículo mínimo para os cursos de Psicologia. Brasília, DF.

Brasil (2004). Ministério da Educação. Parecer CNE/CES n. 62 de 19 de fevereiro de 2004. Diretrizes Curriculares Nacionais para os cursos de graduação em Psicologia. Brasília: DF.

Cassepp-Borges, V. (2013). Desafios para o futuro da Psicologia: contribuições da Psicologia na construção do conhecimento no século XXI. Psicol. Cienc. Prof. [online], vol.33, n.esp., pp. 14-23. operacionalizar processos de investigar, avaliar, intervir) e habilidades instrumentais (para utilizar os melhores recursos disponíveis no exercício profissional). Pautar novos horizontes é um desafio e uma necessidade para o presente e futuro da Psicologia.

Conselho Federal de Psicologia (1992). Carta de Serra Negra. Documento síntese do Encontro Nacional dos Cursos de Psicologia: Repensando a Formação. Serra Negra (SP).

Conselho Federal de Psicologia (2016). Infográfico. A Psicologia brasileira apresentada em números. http://www2.cfp.org.br/infografico/quantos-somos/. Brasília. DF.

Schneider, D.R. (1998). Aformação em Psicologiano Mercosul: perspectivas da integração latino-americana. Temas em Psicologia, v. 6, n. 1, pp. 69-74.

Roberto Moraes Cruz

Editor-chefe

Universidade Federal de Santa Catarina

Como citar: Cruz, R. M. (2016). Presente e Futuro da Psicologia. Psicologia: Ciência e Profissão, 36(4): 783-786.

doi:10.1590/1982-3703003642016

How to cite: Cruz, R. M. (2016). Present and Future of Psychology. Psicologia: Ciência e Profissão, 36(4): 783-786.

doi:10.1590/1982-3703003642016

Cómo citar: Cruz, R. M. (2016). Presente y Futuro de la Psicología. Psicologia: Ciência e Profissão, 36(4): 783-786.

doi:10.1590/1982-3703003642016 